\title{
Standardless Analysis - Better but Still Risky
}

\author{
Nicholas W. M. Ritchie ${ }^{1}$ and Dale E. Newbury ${ }^{1}$ \\ ${ }^{1}$ National Institute of Standards and Technology, Material Measurement Science Division, \\ Gaithersburg, MD 20899-8371
}

In 1995, Newbury et al published a classic study addressing the accuracy of standardless analysis for quantifying the composition with energy dispersive electron probe x-ray microanalysis (ED-EPMA). The results threw cold water on many of the vendor's claims of accuracy and spurred a round of innovation and improvement in the industry.

Today, many vendors have replaced "first principles" standardless analysis with standardless analysis based on "remote standards." Rather than relying on pure physics modeling, "remote standards" rely on standards collected on a canonical detector that are then adapted to match the performance characteristics of the detector in your laboratory. Rather than having to normalize every result to $100 \%$ to compensate for poor knowledge of certain physical processes, some vendors actually can and do report the analytical total when there system has been suitably calibrated. While there are theoretical reasons why remote standards will never match the performance of true standards-based analysis, "remote standards" are a large step forward. However, not all vendors implement remote standards and no vendor documents sufficiently well what they actually do to turn our spectra into measures of composition. These shortcomings make us wonder to what extent a scientific endeavor can be based on black box software that has never been evaluated by an independent third-party to validate its reliability.

Almost 20 years later, standardless analysis is the norm, accounting for more than $95 \%$ of quantitative EDS results. Most vendors promote the simplicity of "one-button" analysis and most customers simply assume the results are accurate. How much better is standardless today than it was in 1995? Should we trust the vendor's claims of accuracy? What role should standardless analysis play?

We have access to many different brands of commercial ED-EPMA hardware / software systems and hundreds of samples of known composition. Evaluations show that the state-of-the-art is better than it was in 1995 but there remains much room for improvement. Consider the results presented in Table 1 which represents the best effort of a major ED-EPMA system vendor on a series of metal sulfides. The results are puzzling. They range from spot-on to mysteriously inept. Take for example $\mathrm{FeS}$ and $\mathrm{FeS}_{2}$. How could the same software quantify FeS with such accuracy but fail so badly on FeS2? Presumably, the software would have used the better understood K lines for both Fe and S. Presumably, the software should have observed an S K peak $150 \%$ more intense and a Fe Ka peak $70 \%$ less intense for FeS 2 than FeS. What went wrong? In contrast, the standards-based algorithms in NIST DTSA-II[2] reliably differentiated the same $\mathrm{FeS}$ and $\mathrm{FeS}_{2}$ spectra and all the other sulfides. A naive analyst who was to make a real-world decision based on these standardless results would see all troilite and no pyrite.

Data from other vendor's hardware / software systems using these and other samples will be presented.

[1] Newbury, D. E., Swyt, C. R., and Myklebust, R. L., "'Standardless' Quantitative Electron Probe Microanalysis with Energy-Dispersive X-ray Spectrometry: Is It Worth the Risk?", Analytical

Chemistry, 67 (1995) 1866-1871. 
[2] Ritchie, N, "Standards-based Quantification in DTSA-II - Part I”, Microscopy Today, Sept. (2011) 30-36

NIST DTSA-II is freely available from http://www.cstl.nist.gov/div837/837.02/epq/dtsa2/index.html

\begin{tabular}{|c|c|c|c|c|c|c|c|c|}
\hline Compound & Metal & \begin{tabular}{|l} 
Standardless \\
Analysis
\end{tabular} & \begin{tabular}{ll} 
& \multicolumn{2}{l}{ Standardless } \\
Rel & Error \\
$(\%)$ &
\end{tabular} & $\begin{array}{l}\text { DTSA-II } \\
\text { Rel Error } \\
(\%)\end{array}$ & Sulfur & $\begin{array}{l}\text { Standardless } \\
\text { Analysis }\end{array}$ & $\begin{array}{l}\text { Standardless } \\
\text { Rel Error } \\
(\%)\end{array}$ & \begin{tabular}{|l} 
DTSA-II \\
Rel Error \\
(\%)
\end{tabular} \\
\hline $\mathrm{FeS}$ & 0.635 & 0.629 & -1 & -0.4 & 0.365 & 0.371 & 1.8 & 0.6 \\
\hline FeS2 & 0.466 & 0.642 & 38 & -1.1 & 0.534 & 0.358 & -33 & 1 \\
\hline $\mathrm{CuS}$ & 0.665 & 0.764 & 15 & 0.3 & 0.335 & 0.236 & -30 & -0.5 \\
\hline $\mathrm{ZnS}$ & 0.671 & 0.762 & 14 & 0.7 & 0.329 & 0.239 & -28 & -1.4 \\
\hline SrS & 0.732 & 0.758 & 3.6 & 0.1 & 0.268 & 0.242 & -10 & -0.2 \\
\hline $\mathrm{CdS}$ & 0.778 & 0.808 & 3.8 & 0.2 & 0.222 & 0.192 & -13 & -0.1 \\
\hline $\mathrm{Sb} 2 \mathrm{~S} 3$ & 0.717 & 0.739 & 3.1 & 0.1 & 0.283 & 0.261 & -7.8 & -0.3 \\
\hline $\mathrm{PbS}$ & 0.866 & 0.914 & 5.5 & 0.2 & 0.134 & 0.086 & -36 & -1.4 \\
\hline
\end{tabular}

Table 1. A comparison of standardless analysis on 8 metallic sulfides with DTSA-II standards-based analysis. These results were collected on a well calibrated detector using the vendor's instructions and quantified using the latest version of each software package.

\section{Standardless Analysis}

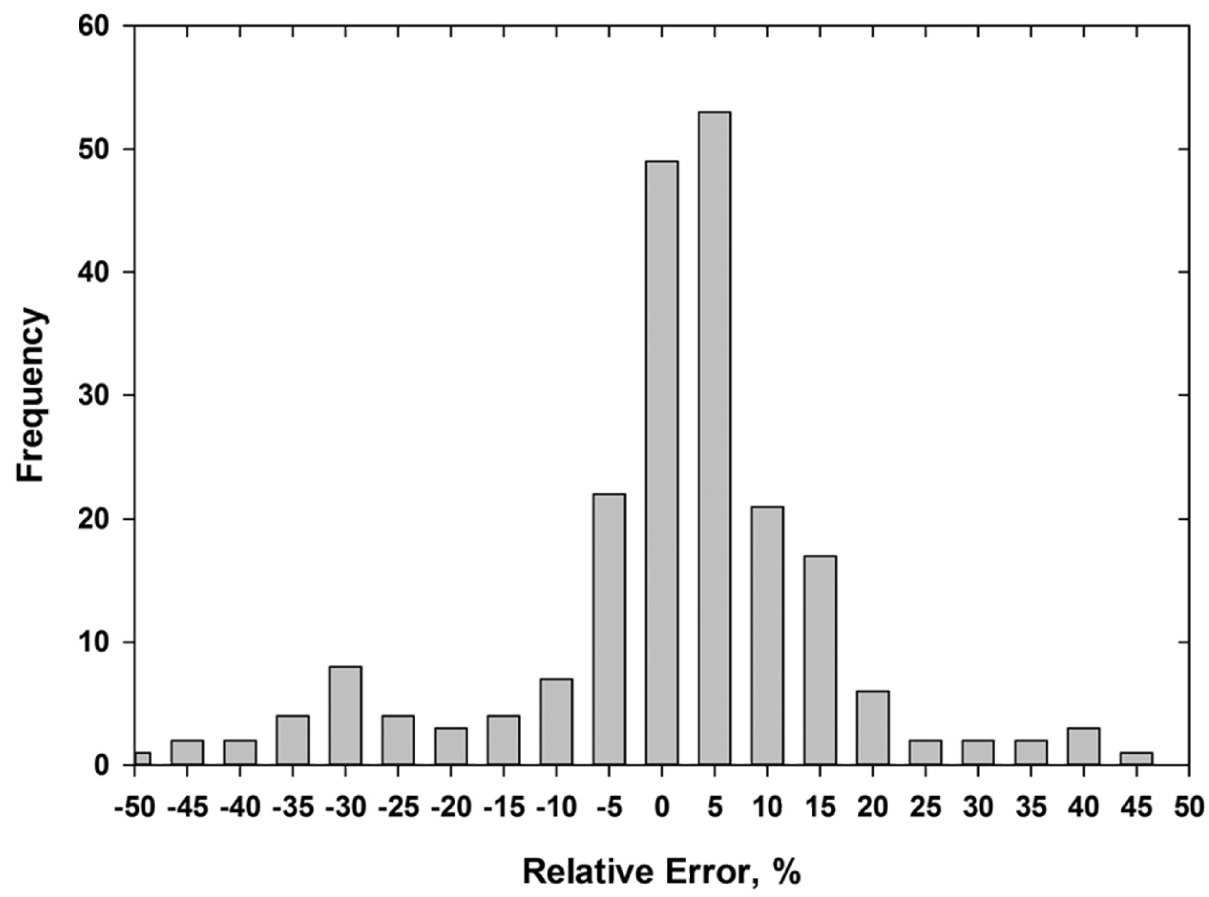

Figure 1. An overview of the performance of various vendor's standardless results on a range of different sample types. 